\title{
Changing Types of Nephritogenic Streptococci in Trinidad
}

\author{
Elizabeth V. Potter, Jesse S. Ortiz, A. Richey Sharrett, Emma G. Burt, \\ Juanita P. Bray, John F. Finklea, Theo Poon-King, and David P. Earle \\ From the Streptococcal Disease Unit, General Hospital, San Fernando, \\ Trinidad-Tobago, and the Department of Medicine, Northwestern University- \\ McGaw Medical Center, Chicago, Illinois 60611
}

\begin{abstract}
A в S T R A C T The relation of seven different $M$ types of streptococci to acute glomerulonephritis associated with skin lesions in South Trinidad has been studied by means of type-specific antibody assays as well as by isolation and identification of the strains. The data indicate that, one after another, five of these strains have prevailed among patients with acute glomerulonephritis during the past five years. At least three of the strains (M-types 55, 49, 57, and/or 60) were associated with epidemic increases in nephritis cases. The appearance of five consecutively predominant types of nephritogenic streptococci during a relatively short period of time is in contrast to the continuing prevalence of M-type 12 strains among nephritogenic streptococci primarily associated with respiratory infections in temperate zones. These observations suggest that the skin sores commonly found on children in tropical Trinidad, provide a particularly suitable environment for development of nephritogenic types. It remains to be seen whether these types will recur or whether new types will continue to emerge in Trinidad.
\end{abstract}

\section{INTRODUCTION}

A major epidemic of acute glomerulonephritis occurred in Trinidad during 1965 (1). This epidemic was biphasic with peak incidences in January and September which were associated with two respective $M$ types of streptococci $(2-4)$. After the epidemic, long-term surveillance studies of streptococcal infections and nephritis were established in Trinidad which document the occurrence of an additional biphasic epidemic in 1967-1968, involving 540 cases of acute glomerulonephritis.

Preliminary reports on this work have been given to the Armed Forces Epidemiological Board, the American Clinical and Climatological Society, the Caribbean Research Council, the Venezuelan Society of Microbiology, and the Chicago Society of Internal Medicine.

Received for publication 24 August 1970 and in revised form 25 January 1971.
The two M types associated with the 1965 epidemic disappeared thereafter (5) while at least three additional new $M$ types became prevalent, one after another, among patients with acute nephritis. The present report describes studies which define and relate these streptococcal types to acute glomerulonephritis during the past five years in Trinidad.

\section{METHODS AND MATERIALS}

Clinical material. The criteria described previously (5) for selection of patients with acute glomerulonephritis have been modified. Initially, two urine samples with both proteinuria and hematuria were required. The second sample sometimes was not obtained for several days by which time abnormalities (particularly proteinuria) had disappeared. Furthermore, hematuria without proteinuria and, even more rarely, proteinuria without hematuria were found in some patients with other signs of acute glomerulonephritis including low and rapidly rising serum complement. Therefore, we extended our criteria to include patients with hematuria and/or proteinuria at the time of admission to the hospital if accompanied by low serum complement or transient edema, azotemia, or hypertension.

Other subjects studied with whom the nephritis patients were compared comprised the following groups: well school children, whole families of patients with nephritis, and whole families without cases of nephritis. These groups varied somewhat each year in relation to special studies being undertaken during respective time periods. Families of nephritis patients were never used as normal control subjects and were not employed in the present studies. School children were most often used for comparison with patients as the great majority of patients with acute glomerulonephritis in Trinidad have been between 2 and $14 \mathrm{yr}$ of age $(1,5)$.

Sera were selected for type-specific antibody assays from patients who had been ill during respective time periods and who had returned for follow-up studies 2-6 months after their illness. Furthermore, the serum samples obtained at the follow-up visit had to be of sufficient quantity to permit these assays after antistreptolysin 0 and beta $1 \mathrm{C}$ globulins had been measured as well as other tests performed in some cases. No attempt was made to match control subjects and patients in regard to skin sores and positive cultures but only to determine that they had or had not had acute nephritis. 
TABLE I

Bactericidal Tests Showing Trace Amounts of Type-Specific Inhibition

\begin{tabular}{|c|c|c|c|c|c|c|c|c|c|c|c|c|}
\hline \multirow[b]{3}{*}{ Inoculum (dilutions) } & \multicolumn{6}{|c|}{ Serum 2049900 , anti-M $57, \mathrm{BI}^{*}=3$} & \multicolumn{6}{|c|}{ Serum J119, anti-M 55, BI* $=5$} \\
\hline & \multicolumn{3}{|c|}{ M-type $57(n=4)$} & \multicolumn{3}{|c|}{ M-type $55(n=6)$} & \multicolumn{3}{|c|}{ M-type $55(n=4)$} & \multicolumn{3}{|c|}{ M-type $49(n=4)$} \\
\hline & $1 / 4$ & $1 / 16$ & $1 / 64$ & $1 / 4$ & $1 / 16$ & $1 / 64$ & $1 / 4$ & $1 / 16$ & $1 / 64$ & $1 / 4$ & $1 / 16$ & $1 / 64$ \\
\hline $\begin{array}{l}\text { Inoculum (number of } \\
\text { organisms) }\end{array}$ & 440 & 140 & 39 & 188 & 56 & 11 & 300 & 102 & 29 & 340 & 117 & 36 \\
\hline \multicolumn{13}{|l|}{$\begin{array}{l}\text { Number of organisms } \\
\text { after } 4 \mathrm{hr} \text { in: }\end{array}$} \\
\hline Normal human serum & $\infty \ddagger$ & $\infty$ & 760 & $\infty$ & $1500 \S$ & 600 & $\infty *$ & $1500 \S$ & 600 & $\infty$ & 1500 & 1200 \\
\hline Rabbit antiserum & 10 & 4 & 1 & 2 & 1 & 1 & 0 & 0 & 0 & 70 & 1 & 0 \\
\hline Patient's serum & 1500 & 560 & 210 & $\infty$ & 1500 & 600 & 800 & 520 & 48 & $\infty$ & $\infty$ & 1200 \\
\hline
\end{tabular}

* Bactericidal index $=\frac{\text { Total number in inoculum } \times 2^{\exp } \text { (number of multiplications during } 4 \mathrm{hr} \text { in normal serum) }}{\text { Total number after } 4 \mathrm{hr} \text { in test serum }}=$

For serum 2049900: $\frac{619 \times 2^{4}}{2570}=\frac{9904}{2570}=3+$.

For serum J119: $\quad \frac{431 \times 2^{4}}{1368}=\frac{6896}{1368}=5$.

$\ddagger$ Too many to count. Plate completely hemolyzed.

Estimated. Hemolysis is confluent and colonies too many to count.

Streptococcal studies. Streptococcal strains were cultured from throats and skin lesions as described previously (5). Grouping and $M$ typing were performed according to Lancefield $(6,7)$ while $\mathrm{T}$ typing was performed according to Moody, Padula, Lizana, and Hall of the National Center for Disease Control (CDS) (8). Antisera from CDC were employed for both procedures.

Type-specific antibodies were measured according to Rothbard (9) as modified by Stollerman, Kantor, and Gordon (10). The resulting bactericidal index (BI) represents the ratio of growth of a streptococcal strain in normal serum to that in the serum being tested, so that a BI of 10 means that 10 times more growth occurred in the presence of normal serum than in the presence of the test serum. In earlier work, an index under 10 was not considered significant, while those indices under 25 were "trace positive." Studies in $1962(11,12)$, employing recall of antibody with small amounts of streptococcal cell-wall vaccine, indicated that indices under 10 also were evidence of previous infection. In an earlier publication concerning Trinidad (3), therefore, indices of 5 or more were considered trace positive. In view of the hundreds of negative bactericidal tests subsequently obtained on sera in Trinidad, the few that show as much as threefold inhibition appear to be significant ( $\mathrm{Ta}$ ble I). In the present study, therefore, a reproducible and type-specific ${ }^{1}$ BI of $3-10$ is considered "trace positive" while a BI of $10-25$ is,$+ 25-50$ is ++ , and $50-100$ is +++ . Anything over 100 is ++++ . Only 20 trace reactions were less than fivefold.

\section{RESULTS}

The incidence of acute glomerulonephritis in South Trinidad since 1964 is shown in Fig. 1, depicted as the running means of hospital admissions during 4-wk periods. The $\mathrm{M}$ and $\mathrm{T}$ types of streptococcal strains re-

\footnotetext{
${ }^{1}$ The serum failed to inhibit strains of at least one other $\mathrm{M}$ type (Table I).
}

total growth in normal serum/total growth in test serum. lated to the epidemic and endemic phases are indicated. The data relating these types to respective phases are presented in the subsequent figures, and will be discussed consecutively for each type.

M-type 12: T-type 12 (Fig. 2). One M-type 12 strain was isolated from a patient with nephritis in March, 1965. This patient also had an M-type 55 strain in a skin lesion. Moreover, the M-type 12 strain was group $G$ rather than group A (13). During 1965, three additional M-type 12 strains were isolated from school children, two of which also were group G. All four

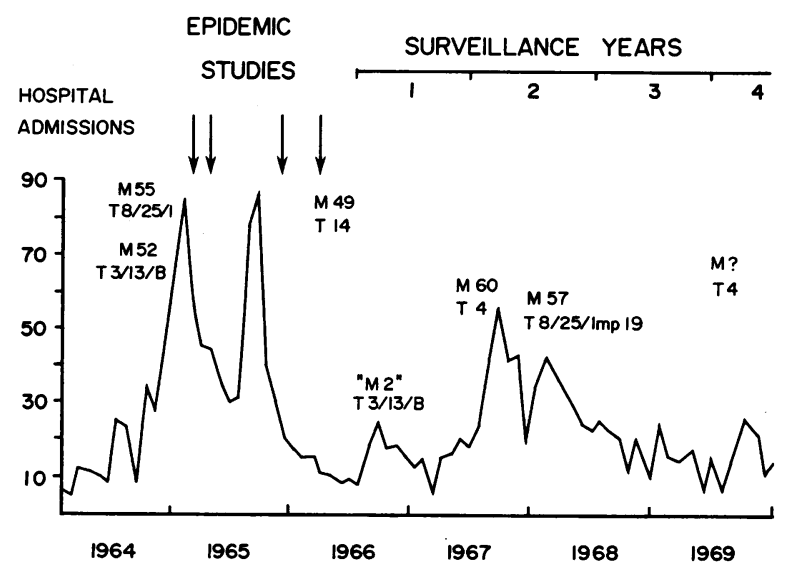

FIGURE 1 Incidence of acute glomerulonephritis in South Trinidad. Running means of the numbers of patients admitted to General Hospital in San Fernando during 4-wk periods are represented on the abscissa while time periods are shown on the ordinate. The $M$ and $T$ types of prevalent strains are indicated for each period. 
strains were found in throat cultures. No M-type 12 strains have been found in Trinidad since 1965.

M-type 12 antibody was present in $30 \%$ of sera from 50 patients (2-22 yr old, average $9.3 \mathrm{yr}$ ) and in $14 \%$ of sera from 22 school children ${ }^{2}$ (5-13 yr old, average $8.6 \mathrm{yr}$ ) in the spring of 1965 . Of these 18 sera with M-type 12 antibody, only 2 showed more than a trace of inhibition. Since July, 1966, the only anti-M-type 12 activity found has been trace amounts in 2 of 75 sera from patients tested (1-34 yr old, average $7.7 \mathrm{yr}$ ).

$M$-type 55: T-type 8/25/Imp 19 (Fig. 3). Of 26 strains isolated from 28 patients early in 1965, 62\% were M-type 55 . Since that time, only one additional M-type 55 strain has been found among 250 strains from patients tested.

M-type 55 antibody was found in sera from $64 \%$ of 50 patients with acute nephritis (2-22 yr old, average $9.3 \mathrm{yr}$ ) and from $25 \%$ of 24 school children (5-13 yr old, average $8.9 \mathrm{yr}$ ) in the spring of 1965 . M-type 55 antibody also was found in sera from $50 \%$ of 51 patients in the fall of 1965 and from $26 \%$ of 50 patients (1-17 yr old, average $7.2 \mathrm{yr}$ ) in 1966. In 1968, M-type 55 antibody was found in $29 \%$ of 52 control subjects (1-13 yr old, average $8.6 \mathrm{yr}$ ) as well as in $20 \%$ of 61 patients
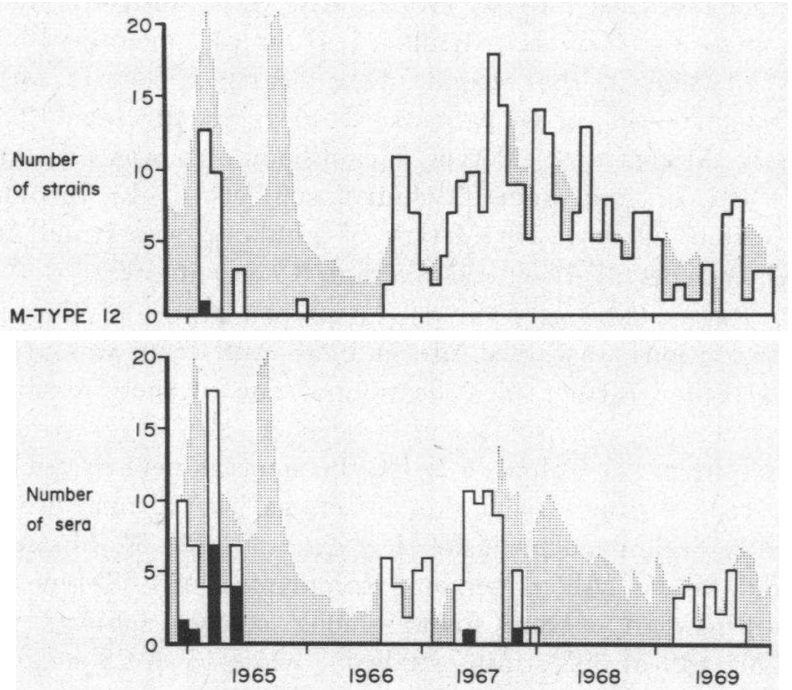

FIGURE 2 Relation of M-type 12 strains to acute nephritis in South Trinidad. The number of streptococcal strains isolated from patients with nephritis during monthly periods is represented in the upper graph by the open bars while the number of these strains which were M-type 12 has been blackened. The open bars in the lower graph represent the number of sera from patients with nephritis tested for $M$ type 12 antibody during different time periods while the number with antibody has been blackened. The shaded background in both graphs indicates the incidence of nephritis cases during these periods as shown in Fig. 1.

${ }^{2} 10$ with sores, 5 of which yielded group A streptococci; 12 with streptococcal strains in throat cultures, 5 of which were group A.
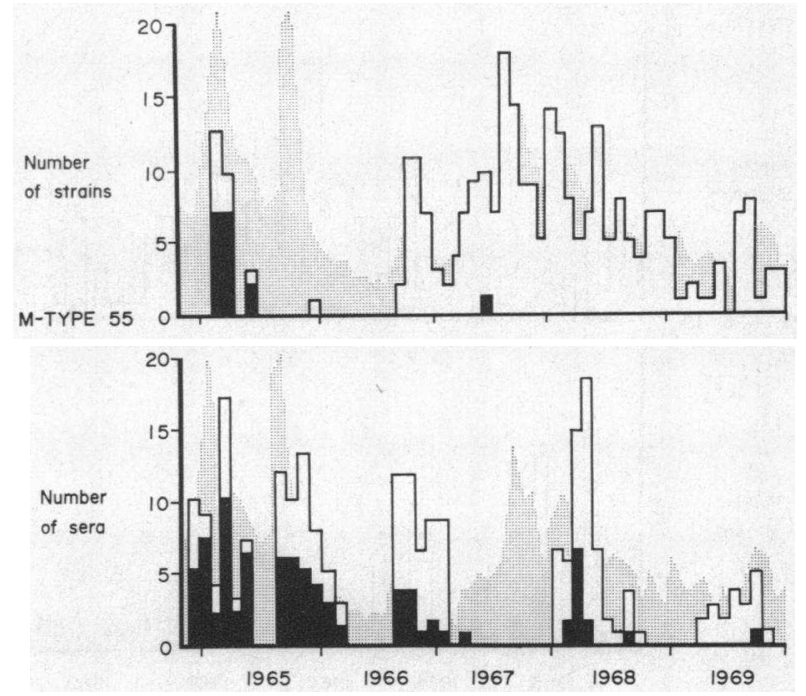

FIGURE 3 Relation of M-type 55 strains to acute nephritis in South Trinidad. For explanation, see Fig. 2.

(2-46 yr old, average $10.8 \mathrm{yr}$ ). Only 1 of 20 patients (1-16 $\mathrm{yr}$ old, average $8.9 \mathrm{yr}$ ) had trace amounts of antibody in 1969 . While $23 \%$ of the positive sera from patients showed inhibition of ++++ in the spring of 1965 , and $12 \%$ in the fall, only two sera have exceeded ++ inhibition since that time.

M-type 52: T-type 3/13/B326.1 (Fig. 4). Of the 26 streptococcal strains isolated from 28 patients early in 1965, 20\% were M-type 52. In December, 1965, this type was isolated from 1 of 3 patients cultured and from 3 of his 6 siblings, 2 of whom developed nephritis within 3 wk of that time. Subsequently, this strain has been

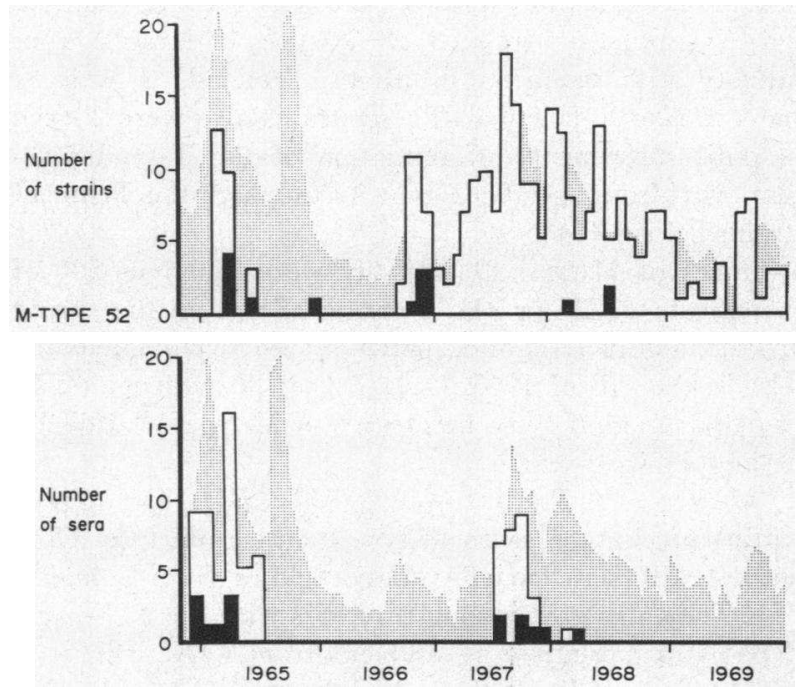

FIgURE 4 Relation of M-type 52 strains to acute nephritis in South Trinidad. For explanation, see Fig. 2. 

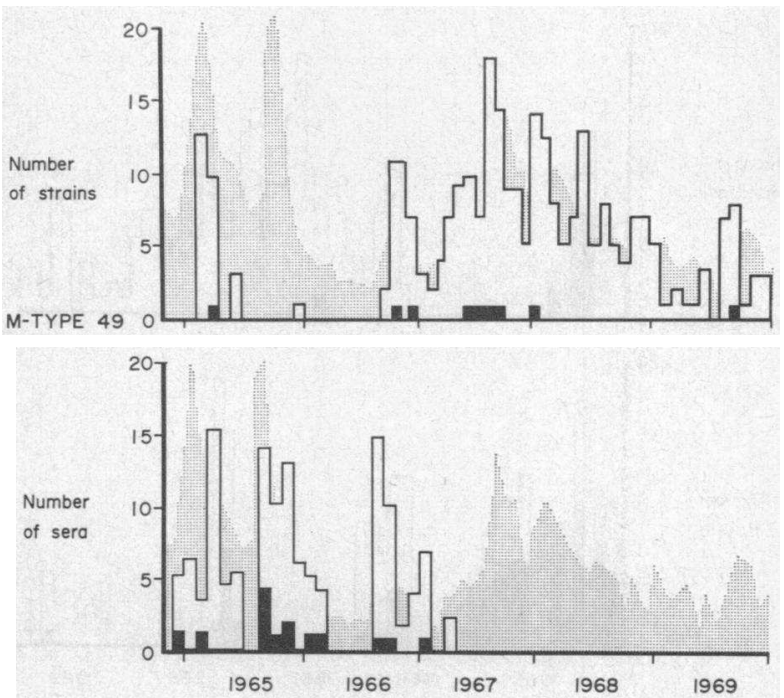

FIgURE 5 Relation of M-type 49 strains to acute nephritis in South Trinidad. For explanation, see Fig. 2.

found sporadically in both school children and patients with nephritis.

Antibody to M-type 52 was present in $16 \%$ of 49 sera from patients (2-22 yr old, average $9.1 \mathrm{yr})$ and in none of 28 sera from school children (5-14 yr old, average $8.8 \mathrm{yr}$ ) in the spring of 1965 . M-type 52 antibody also was found in $26 \%$ of 30 patients (3-47 yr old, average $9.4 \mathrm{yr}$ ) in later periods. Only one of these tests showed more than + inhibition.

$M$-type 49: T-type 14 (Fig. 5). One strain proved to be M-type 49 in March, 1965. This strain was T-type 14 at both Colindale and CDC. ${ }^{3}$ No strains were isolated by us during the second wave of the epidemic in the fall of 1965. At that time, however, Parker, Bassett, Maxted, and Arneaud (4) isolated 18 M-type 49 strains from patients with nephritis in South Trinidad as well as many in North Trinidad. These strains also were T-type 14 until subsequent differentiation of the T-typing serum provided a specific T-type 49 to which the Trinidad strains belong (14).

Traces of M-type 49 antibody were found in $5 \%$ of 40 patients (1-27 yr old, average $9.7 \mathrm{yr}$ ) in the spring of 1965 , and in $17 \%$ of 52 patients $(2-15 \mathrm{yr}$ old, average 6.1 ) in the fall of 1965 . Only $7 \%$ of 40 patients (2-17 yr old, average $6.2 \mathrm{yr}$ ) had traces of M-type 49 antibody in the following year.

"M-type 2": T-type 3/13/B3264 (Fig. 6). These strains precipitated with M-type 2 antiserum from CDC but not with sera from Dr. Lancefield or from Colindale (5). They also gave strong reactions with the T, W, and $Z$ pools of agglutinating antisera from $C D C$ which we were using while both Colindale and $\mathrm{CDC}$ obtained

\footnotetext{
${ }^{3}$ Central Public Health Laboratory, London, England.
}

T-pattern 3/13/B3264 with different batches of antisera. Satisfactory bactericidal antiserum was not obtained from rabbits although several attempts at immunization were made. We describe these perhaps spurious reactions and refer to the strains as "M-type 2" so that similar strains may be identified by others employing CDC antisera. These strains were found during the endemic year of 1966-1967 exclusively. At this time, $21 \%$ of 39 strains recovered from patients with acute nephritis ( $60 \%$ of those that were $\mathrm{M}$ typable) were "M-type 2," compared with $4 \%$ of strains from school children (5).

Type-specific antibody to these strains could not be assayed in the absence of satisfactory antiserum for the controls.

M-type 57: T-type 8/25/Imp 19 (Fig. 7). In the last half of 1967, M-type 57 became prevalent, constituting more than $50 \%$ of the strains recovered from patients with acute nephritis. It reached a peak incidence early in 1968 and has declined slowly since that time. M-type 57 strains also were prevalent in families without nephritis ( $44 \%$ of 100 strains).

M-type 57 antibody was found in only one of 130 sera from patients (1-27 yr old, average $7.6 \mathrm{yr}$ ) ill before June, 1967. During the first phase of the second epidemic (last half of 1967), M-type 57 antibody was found in $8 \%$ of 74 patients (1-47 yr old, average 10.0 yr) while in the second phase (early 1968), it was found in $13 \%$ of 64 patients (2-46 yr old, average 10.8 yr). At this time, M-type 57 antibody also was present in $8 \%$ of sera from 50 control subjects (1-13 yr old, average $8.6 \mathrm{yr}$ ). No M-type 57 antibody was found in 20 patients (1-16 yr old, average $8.9 \mathrm{yr}$ ) in 1969.

T-type 4 strains (Fig. 8). A preponderance of T-type 4 isolations was noted late in 1968. Antiserum was prepared for further identification of one of these strains which had been isolated in November, 1967. This strain was found, at Colindale, to be the same as nephritogenic T-type 4 strains from skin infections in Alabama, presently designated provisional M-type 60 (W. R. Maxted and $\mathrm{H}$. C. Dillon, personal communication). T-type 4 strains rarely were found among control subjects in 1969 (19 of 395 strains studied), while 18 of 25 strains

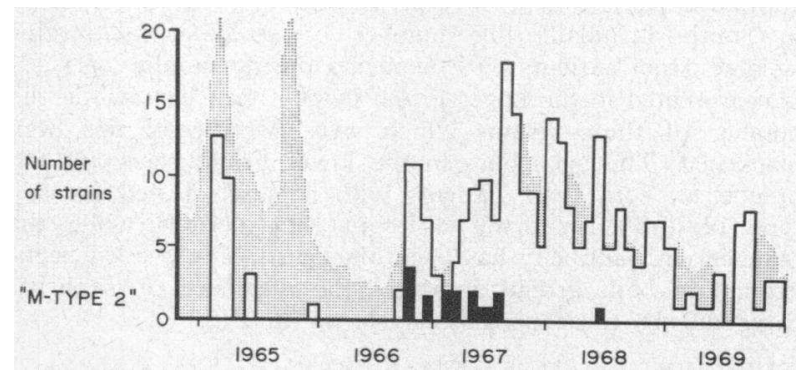

FIgURE 6 Relation of “M-type 2" strains to acute nephritis in South Trinidad. For explanation, see Fig. 2. 
isolated from patients during the last 6 months of 1969 and 4 of 5 strains isolated in January, 1970, were of this $\mathrm{T}$ type. The more recently isolated strains, however, appear to be of still another $M$ type, which has not yet been assigned a provisional number (D. J. C. Bassett, personal communication).

M-type-specific antibody studies with our Trinidad prototype of provisional M-type 60 have elicited only trace amounts of inhibition in the sera of 2 of 55 patients (1-21 yr old, average $7.1 \mathrm{yr}$ ), including 22 from whom T-type 4 strains were isolated.

\section{DISCUSSION}

M-typing of streptococcal strains has been considered the most significant identification to be made in epidemiological studies of respiratory infections as it is the M-type-specific antibody which confers immunity and limits the spread of infection. This immunological aspect of skin infections, however, is less clear. As in earlier studies, many skin-infecting strains continue to be of hitherto unknown $M$ types and, therefore, are not identifiable by this means at the time of isolation. Such was the case in the present study. Only after specific antisera had been prepared with which relationships to other new strains were defined or excluded, could the new $M$ types be established. The $T$-agglutinating antigen, in contrast, is not associated with immunity and may be shared by several $M$ types. Thus, it does not supply as valuable epidemiological information as the $M$ type. It is, however, nearly always detectable and provides a useful label for newly isolated strains. Furthermore, recent observations of Dillon, Reeves, and Maxted (15) reemphasize those of Watson and Lance-
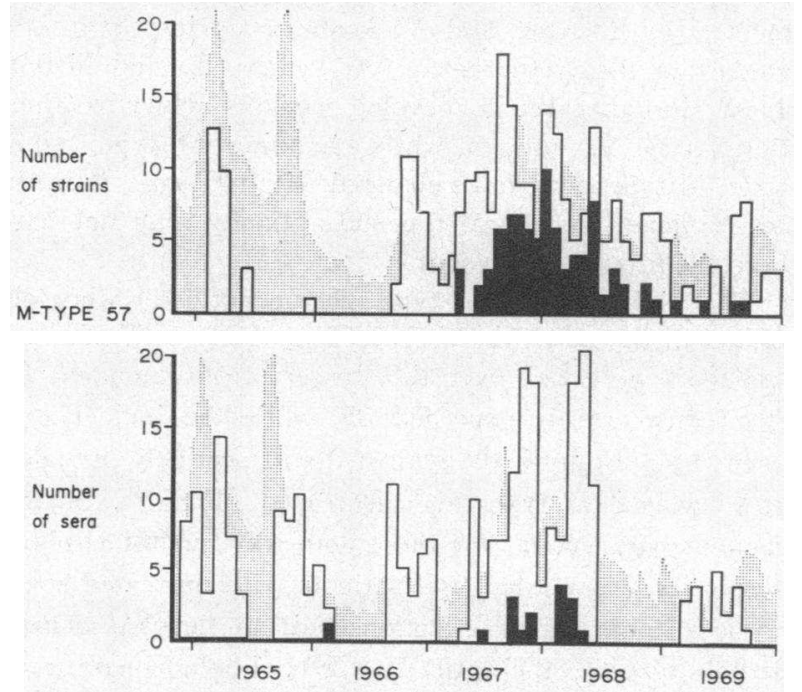

FIgure 7 Relation of M-type 57 strains to acute nephritis in South Trinidad. For explanation, see Fig. 2.
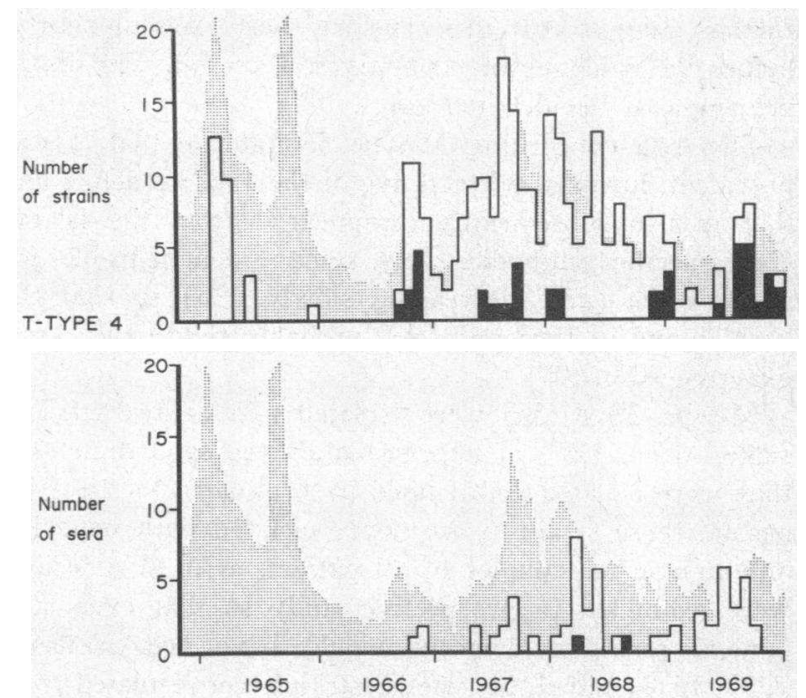

FIGURE 8 Relation of T-type 4 strains to acute nephritis in South Trinidad. For explanation, see Fig. 2. (M-type 60 antibody assayed.)

field in 1944 (16) which revealed that strains of a single $M$ type may be further distinguished by the possession of different $\mathrm{T}$ types. The two methods supplement each other and are particularly helpful when used together.

In Trinidad, multiple skin lesions as well as frequent colonization of single lesions by several different groups and types of streptococci $(17,18)$ lessen the etiological significance of any single isolation. The type-specific antibody assays were employed to provide evidence of prior infection with a specific type, as compared with the carrier state, as well as to identify additional patients with specific infections from whom M-typable streptococcal strains had not been isolated.

When these studies were begun, M-type 12 was considered the classic nephritogenic $M$ type, as first described by Rammelkamp and Weaver (19) in 1953 and subsequently by others (20-22) in relation to respiratory infections throughout the world. In our own laboratory, 15 of 16 strains from sporadic cases of acute nephritis in Chicago had been M-type 12 (23). Therefore, although only one strain of this type was isolated from patients in Trinidad in March, 1965, we suspected that type 12 infections might have occurred, nonetheless. That $30 \%$ of the patients had traces of type 12 antibody was not considered of etiological significance since $18 \%$ of normal school children in Chicago had been found to have more than trace amounts of M-type 12 antibodies (12). M-type 12 strains had been prevalent consistently in Chicago (24), however, while they were isolated only rarely in Trinidad (3-5). The decreasing incidence of M-type 12 antibodies subsequently found in Trinidad 
further suggest that this type had been present shortly before the epidemic of nephritis in 1965, but was disappearing as the epidemic began.

The data concerning M-type 55 indicate that it was prevalent during the first wave of the 1965 epidemic and that it also subsequently disappeared from the island. Type-specific antibodies may remain demonstrable for many years (25), decreasing slowly (26) so that the titers found in 1968 and 1969 probably reflect infections experienced in 1965.

M-type 52 strains were isolated and defined at Red Lake, Minn. (27) at approximately the same time that they were isolated and defined in Trinidad (3). In Minnesota, these strains were not associated with nephritis although urine samples of all patients with skin lesions were examined in prospective study so that even subclinical renal involvement would have been detected (28). In Trinidad, M-type 52 strains were isolated from patients with clinically apparent nephritis in 1965 as well as from "normal" children (3), while $16 \%$ of 49 representative patients had M-type 52 antibodies. However, 6 of the 8 patients with M-type 52 antibodies also had M-type 55 antibodies. Furthermore, the M-type 52 strains continued to be found in skin infections of both patients and control subjects in Trinidad after the 1965 epidemic had subsided. We concluded, therefore, in concurrence with Dr. Franklin Top and his associates (personal communication), that these strains probably were prevalent in skin infections but not specifically related to the epidemic of nephritis. The presence of M-type 52 antibody in $26 \%$ of 30 patients with nephritis in Trinidad during 1967-1968 as well as its absence in all of 28 "normal" school children suggests that isolation of these strains from patients with nephritis was more than fortuitous and that they were nephritogenic. However, these observations may merely reflect an increased incidence of prior skin infections in the patients with nephritis, a concept supported by the increased incidence of skin infections found in families of patients with nephritis as compared with control families in Trinidad (5).

The relation of M-type 49 strains to nephritis has been amply documented at Red Lake (29-33), in Alabama (34), and in other parts of the world (14). M-type 49 strains also have been identified in our laboratory from two boys who had acquired skin lesions in Puerto Rico and developed nephritis following their return to Chicago, from skin lesions on a child with nephritis in the Panama Canal Zone, and from the sibling of a young patient with acute nephritis in Chicago. Identification of this type in $38 \%$ of the strains from nephritic patients in Trinidad, compared with $15 \%$ of the strains from school children (4) indicates its importance in the second wave of the 1965 epidemic. Failure to find M-type
49 antibodies in more than $17 \%$ of patients ill at that time may have resulted from factors affecting antibody response (vide infra) rather than to absence of infection with this streptococcal type.

M-type 55 disappeared rapidly while M-type 49 disappeared more slowly during the year 1966-1967. A subepidemic increase in the number of cases of nephritis was observed in the fall of 1966, associated with the "M-type 2" strains which soon disappeared. These were followed by the appearance of M-type 57 strains along with an increased incidence of acute nephritis of epidemic proportion.

In contrast to the M-type 55 strains, M-type 57 strains were new to the population of Trinidad in the fall of 1967. Neither M-type 57 strains nor antibodies (with one exception) were found before that time, while both were present subsequently. This type also nearly disappeared as T-type 4 strains became predominant. The equal prevalence of M-type 57 strains among control subjects and nephritis patients somewhat clouds the nephritogenic role of these strains. T-type 4 strains, including M-type 60 strains, also were found during the 1967-1968 epidemic. Whether these strains, rather than M-type 57 , were specifically associated with one or both of the epidemic waves is not clear. The type-specific antibody studies, which might have cast much light upon this point, have not been very helpful since nearly equal, low incidences of M-type 57 antibody were found during both epidemic peaks, while little antibody was found against M-type 60 during either peak. The T-type 4 strains have not been completely defined, however. Several were found in 1966, again in 1968, and yet again at the end of 1969. These strains include M-type 60 and at least one additional $M$ type. Alteration of M-type protein within strains of a given $\mathrm{T}$ type has been documented by Maxted and Valkenburg during long-term studies in the Netherlands (35) where T- and M-type 12 strains appeared to develop variants which retained the T-type 12 antigen while changing $M$ type. Similarly, $M$ types may have changed within T-type 4 strains in Trinidad, so that M-type 60 antibody may not have been the proper one to seek.

The highest titers of type-specific antibody were obtained in the tests for M-type 55 antibody in 1965. Several BI's were well over 100 . In sera from later periods, the indices rarely exceeded 25 , while the incidence of even traces of antibody against the respectively prevalent streptococcal M types also decreased (Fig. 9). Several factors may account for these generally modest antibody responses. Nearly half the patients with untreated streptococcal pharyngeal infections fail to develop demonstrable type-specific antibody (26) while adequate treatment with penicillin may further decrease this immune response (26). Thus, after the streptococcal etiology of 
the 1965 epidemic in Trinidad was recognized, earlier treatment may have reduced the type-specific immune response of patients with acute nephritis. In addition, some streptococcal strains appear to be less antigenic in rabbits, in relation to M-type-specific antibody, than other strains. They also may be less antigenic in man. M-type 49 and "M-type 2" strains are in this category, but not the M-type 55, 57, or 60 strains. Finally, antistreptolysin 0 titers have been found to be lower in patients with streptococcal skin infections than in patients with pharyngeal infections, whether or not accompanied by nephritis (36-38), even when strains of the same M type were involved (37). These studies suggest an influence on the antistreptolysin 0 response by factors related to the site of infection. These or other factors related to the skin site of infections also may affect the type-specific antibody response. However, the higher titers of M-type 55 antibody found in patients with nephritis associated with skin infections at the beginning of our studies in Trinidad (2) indicate that the site of infection is not the sole factor contributing to the lower antibody titers subsequently observed in the same population (5).

The appearance of five different M-types (types 55, $49,57,60$, and "2") associated with nephritis in Trinidad during a relatively short period is in contrast to the continued prevalence of M-type 12 among nephritogenic streptococcal strains in areas where acute nephritis generally is associated with respiratory infections. It also differs from the situation at Red Lake where, despite seasonal outbreaks of streptococcal skin infections, only sporadic cases of nephritis associated with M-type 12 respiratory infections were observed during several years between two M-type 49 epidemics. Thus, the skin infections in Trinidad appear to provide a peculiarly suitable environment for the development of nephritogenic strains, either through mutation of old types or through introduction of new ones to the island. While each new type appears to have been nephritogenic (with the possible exception of M-type 52), this observation may result from concentration of our efforts to identify new types on the strains from patients with acute glomerulonephritis. The majority of strains from school children also are not $M$ typable and some of these may represent new $M$ types which are not nephritogenic. Nonetheless, the number of nephritogenic strains remains unusual.

Several of the strains isolated in Trinidad were of previously unknown $M$ types, so that they may have developed there. However, all of these new $M$ types have been found in strains from skin lesions in other parts of the world. M-type 55 has been isolated from patients with nephritis in Israel (39), patients with nephritis in Egypt, Singapore, and South Africa (M. T.

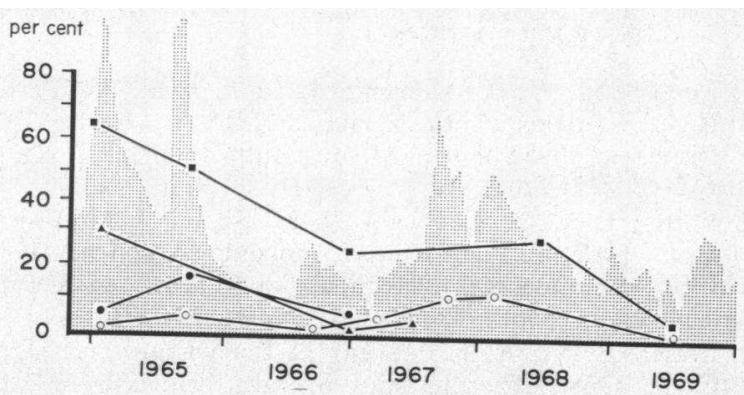

FIGURE 9 Frequency of type-specific antibody to $M$ types of streptococci prevalent during respective time periods in South Trinidad. The per cent of patients' sera tested which showed evidence of type specific antibody is indicated on the abscissa while related time periods are indicated on the ordinate. $\Delta$ represents tests for M-type 12 antibody; represents tests for M-type 55 antibody; - represents tests for $M$-type 49 antibody; $O$ represents tests for M-type 57 antibody.

Parker and W. R. Maxted, personal communication), two patients without nephritis in Chicago (M. D. Moody, personal communication), and a child with acute nephritis in Venezuela (our laboratory). M-type 52 has been found in skin infections without nephritis at Red Lake, Minn. (27) and with nephritis in Memphis, Tenn. (40), while M-type 60 has been a major nephritogenic type in Alabama (41). Finally, M-type 57 recently has been associated with skin infections and nephritis at Red Lake (42). None of these types, nor M-types 49, " 2 ," or 12 , have recurred in Trinidad as yet. It was 13 years, however, before M-type 49 returned to Red Lake after its initial identification in 1953 (30). It remains to be seen, therefore, whether new strains will continue to emerge in Trinidad or whether those presently described will prevail again.

\section{ACKNOWLEDGMENTS}

In Trinidad, the authors gratefully acknowledge: permission for publication of this material from the honorable Minister of Health of Trinidad-Tobago, Dr. Max Awon; the advice and assistance of Dr. Mervyn Henry and Mr. Gerald Chen in administrative matters; the assistance of Dr. Stella Abidh, Regional Director of Health Services of South Trinidad, and her staff in the field studies; and the technical assistance of Arthur Ayers, Peter Meighoo, Steve Dookie, Jaglal Bhikie, Steve Reed, Trevor Eastman, and Zainol Mohammed. In Chicago, we are grateful to Mrs. Susan Reimer for her technical assistance. We also gratefully acknowledge the advice and cooperation of Drs. Rebecca Lancefield, Max Moody, Franklin Top, Thomas Parker, David Bassett, and Mr. William Maxted in these studies.

This study was supported by the Ministry of Health of Trinidad-Tobago, United States Public Health Service contract PH 108-66-217, and by grants from the United States Public Health Service ( $\mathrm{HE} \mathrm{7057)} \mathrm{and} \mathrm{from} \mathrm{the} \mathrm{Otho}$ S. A. Sprague Foundation. 


\section{REFERENCES}

1. Poon-King, T., I. Mohammed, R. Cox, E. V. Potter, N. M. Simon, A. C. Siegel, and D. P. Earle. 1967. Recurrent epidemic nephritis in South Trinidad. N. Engl. J. Med. 277: 728.

2. Potter, E. V., A. C. Siegel, N. M. Simon, J. McAninch, D. P. Earle, T. Poon-King, I. Mohammed, and S. Abidh. 1968. Streptococcal infections and acute glomerulonephritis in South Trinidad. J. Pediat. 72: 871.

3. Potter, E. V., A. F. Moran, T. Poon-King, and D. P. Earle. 1968. Characteristics of beta hemolytic streptococci associated with acute glomerulonephritis in Trinidad, West Indies. J. Lab. Clin. Med. 71: 126.

4. Parker, M. T., D. C. J. Bassett, W. R. Maxted, and J. D. Arneaud. 1968. Acute glomerulonephritis in Trinidad: serological typing of group A streptococci. J. Hyg. 66: 657 .

5. Ortiz, J. S., J. F. Finklea, E. V. Potter, T. Poon-King, D. Ali, and D. P. Earle. 1970. Endemic nephritis and streptococcal infections in South Trinidad. Surveillance studies during the first year following a major epidemic. Arch. Intern. Med. 126: 640.

6. Lancefield, R. C. 1933. A serological differentiation of human and other groups of hemolytic streptococci. $J$. Exp. Med. 57: 571 .

7. Lancefield, R. C. 1928. Antigenic complex of Streptococcus haemolyticus. Demonstration of type specific substance in extracts of streptococcus hemolyticus. J. Exp. Med. 47: 91.

8. Moody, M. D., J. Padula, D. Lizana, and C. T. Hall. 1965. Epidemiologic characterization of group A streptococci by $T$-agglutination and $M$ precipitation tests in the Public Health Laboratory. Health Lab. Sci. 2: 149.

9. Rothbard, S. 1945. Bacteriostatic effect of human sera on group A streptococci: type specific antibodies in sera of patients convalescing from group A streptococcal pharyngitis. J. E.rp. Med. 82: 93 .

10. Stollerman, G. H., F. S. Kantor, and B. D. Gordon. 1958. Accessory plasma factors involved in the bactericidal test for type-specific antibody to group A streptococci. I. Atypical behavior of some human and rabbit bloods. 1958. J. Exp. Med. 108: 475.

11. Potter, E. V., G. H. Stollerman, and A. C. Siegel. 1962. Recall of typespecific antibodies in man by injections of streptococcal cell walls. J. Clin. Invest. 41: 301.

12. Potter, E. V. 1965. Type 12 streptococci and acute glomerulonephritis I. Presence and recall of type-specific streptococcal antibodies in patients with healed acute glomerulonephritis. J. Lab. Clin. Med. 65: 40.

13. Maxted, W. R., and E. V. Potter. 1967. The presence of type $12 \mathrm{M}$-protein antigen in group $\mathrm{G}$ streptococci. J. Gen. Microbial. 49: 119.

14. Maxted, W. R., C. A. M. Fraser, and M. T. Parker. 1967. Streptococcus pyogenes, type 49. A nephritogenic streptococcus with a wide geographical distribution. Lancet. 1: 641.

15. Dillon, H. C., M. S. Reeves, and W. R. Maxted. 1968. Acute glomerulonephritis following skin infection due to streptococci of M-type 2. Lancet. 1: 543.

16. Watson, R. F., and R. C. Lancefield. 1944. Studies on the antigenic composition of Group A hemolytic streptococci. III. Types with serologically identical $\mathbf{M}$ but distinct $\mathrm{T}$ antigens: types 10 and 12. J. Exp. Med. 79: 89.
17. Ortiz, J. S., D. P. Earle, and J. F. Finklea. 1967. Streptococcal surveillance of two South Trinidad school populations. Abstracts of the 12th Scientific Meeting of the Standing Advisory Committee for Medical Research in the British Caribbean. Georgetown, Guyana.

18. Parker, M. T. 1969. Streptococcal skin infection and acute glomerulonephritis. Brit. J. Dermatol. 81 (Suppl. 1) : 37 .

19. Rammelkamp, C. H., Jr., and R. S. Weaver. 1953. Acute glomerulonephritis. The significance of the variations in the incidence of the disease. J. Clin. Invest. 32: 345.

20. Wilmers, M. J., A. C. Cunliffe, and R. E. Williams. 1954. Type 12 streptococci associated with acute hemorrhagic nephritis. Lancet. $2: 17$.

21. Kodama, M. 1957. Symposium, streptococcal infection and acute nephritis. J. Jap. Assoc. Infec. Dis. 31: 283.

22. Valkenburg, H. A., W. R. Goslings, A. W. Bots, C. E. deMoor, and J. C. Lorrier. 1963. Attack rate of streptococcal pharyngitis, rheumatic fever, and glomerulonephritis in the general population. II. The epidemiology of streptococcal pharyngitis in one village during a twoyear period. N. Engl. J. Med. 268: 694.

23. Earle, D. P. 1964. Discussion of Dr. Rammelkamp's paper. In The Streptococcus, Rheumatic Fever and Glomerulonephritis, J. W. Uhr, editor. Williams \& Wilkins Co., Baltimore. 300.

24. Siegel, A. C., E. E. Johnson, and G. H. Stollerman. 1961. Controlled studies of streptococcal pharyngitis in a pediatric population. 1. Factors related to the attack rate of rheumatic faver. N. Engl. J. Med. 265: 559.

25. Lancefield, R. C. 1959. Persistence of type specific antibodies in man following infections with group A streptococci. J. Exp. Med. 110: 271.

26. Siegel, A. C., E. E. Johnson, and G. H. Stollerman. 1961. Controlled studies of streptococcal pharyngitis in a pediatric population. 2. Behavior of the type specific immune response. N. Engl. J. Med. 265: 566.

27. Top, F. H., L. W. Wannamaker, W. R. Maxted, and B. F. Anthony. 1967. M antigens among group A streptococci isolated from skin lesions. J. Exp. Med. 126: 667.

28. Anthony, B. F., L. V. Perlman, and L. W. Wannamaker. 1967. Skin infections and acute nephritis in American Indian children. Pediatrics. 39: 263.

29. Updyke, E. L., M. S. Moore, and E. Conroy. 1955. Provisional new type of group A streptococci associated with nephritis. Science (Washington). 121: 171.

30. Anthony, B. F., E. L. Kaplan, S. S. Chapman, P. G. Quie, and L. W. Wannamaker. 1967. Epidemic acute nephritis with reappearance of type 49 streptococcus. Lancet. 2 : 787.

31. Anthony, B. F., E. L. Kaplan, L. W. Wannamaker, F. W. Briese, and S. S. Chapman. 1969. Attack rates of acute nephritis after type 49 streptococcal infection of the skin and of the respiratory tract. J. Clin. Invest. 48: 1697.

32. Kaplan, E. L., B. F. Anthony, S. S. Chapman, and L. W. Wannamaker. 1970. Epidemic acute glomerulonephritis associated with type 49 streptococcal pyoderma. 1. Clinical and laboratory findings. Amer. J. Med. 48: 9.

33. Fish, A. J., R. C. Herdman, A. F. Michael, R. J. Pickering, and R. A. Good. 1970. Epidemic acute glomerulonephritis associated with type 49 streptococcal pyoderma. II. Correlative study of light, immunofluorescent and electro microscopic findings. Amer. J. Med. 48: 28. 
34. Dillon, H. C., Jr., M. D. Moody, W. R. Maxted, and M. T. Parker. 1967. The epidemiology of impetigo and acute glomerulonephritis. Amer. J. Epidemiol. 86: 710.

35. Maxted, W. R., and H. A. Valkenburg. 1969. Variation in the M-antigen of group A streptococci. J. Med. Microbiol. 2: 199.

36. Dillon, H. C., and M. S. Reeves. 1969. Streptococcal antibody titers in skin infections and acute glomerulonephritis. Pediat. Res. 3: 362.

37. Kaplan, E. L., B. F. Anthony, S. S. Chapman, E. M. Ayoub, and L. W. Wannamaker. 1970. The influence of the site of infection on the immune response to group $A$ streptococci. J. Clin. Invest. 49: 1405.

38. Rodriguez-Iturbe, B., and R. Garcia-Ramirez. 1969.
Acute glomerulonephritis. A clinical study of 470 cases. Abstracts of the Fourth International Congress of $\mathrm{Ne}$ phrology, Stockholm, Sweden. 144.

39. Bergner-Rabinowitz, S. 1971. J. Infec. Dis. In press.

40. Roy, S., III, H. P. Wall, and J. N. Etteldorf. 1969. Second attacks of acute glomerulonephritis. J. Pediat. 75: 758.

41. Derrick, C. W., M. S. Reeves, and H. C. Dillon, Jr. 1970. Complement in overt and asymptomatic nephritis - after skin infection. J. Clin. Invest. 49: 1178.

42. Ferrieri, P., A. S. Dajani, S. S. Chapman, J. B. Jensen, and L. W. Wannamaker. 1970. Appearance of nephritis associated with type 57 streptococcal impetigo in North America. N. Engl. J. Med. 283: 832. 